and 71 for Aedes aegypti L.; 265 and 55 for Culex pipiens L.; and 24 and 4 for Culex tarsalis Cop.

Substances that can aggregate individuals of a field population at an appropriate stage should make a valuable contribution to control programmes, especially perhaps to those involving sterilization at a natural focus. Being non-persistent, relatively inexpensive and, only briefly toxic to aquatic life (not necessarily a disadvantage in artificial pools), capric acid appears to hold great promise as such a substance.

\section{G. Maw}

Research Institute,

Canada Department of Agriculture,

Belleville, Ontario.

Received March 13; revised May 26, 1970.

1 Quraishi, M. S., and Thorsteinson, A. T., J. Bcon. Entomol., 58, 185 (1965). "Quraishi, M. S., and Thorsteinson, A. T., J. Elcon. Entomol., 68, 400 (1965). House, H. L., Canad. Entomol., 98, 384 (1967).

House, H. L., and Graham, A. R., Canad. Entomol., 99, 994 (1967).

5 Brown, A. W. A., Inset Control by Chemicals (Wlley, New York, 1951). - Metcalfe, C. L., and Flint, W. P., Destructive and Useful Insects, McGraw-

? Briand, T. J., Ecology, 45, 365 (1964).

\section{Increasing Frequency of the Typical Form of the Peppered Moth in Manchester}

THE murk of nineteenth-century Manchester fostered the melanic form carbonaria of the peppered moth, Biston betularia (L.). The subsequent spread of this form, at the expense of the pale coloured typicals, throughout industrial regions in Britain and elsewhere in western Europe, is a striking example of rapid evolutionary response to a changing environment.

Records of $B$. betularia in Britain indicate that the incidence of the melanic form in industrial regions increased swiftly during the past $100 \mathrm{yr}$, but precise data on the rate of change are regrettably lacking ${ }^{1}$. In Manchester the black form was prevalent by 1900 , although typicals still occurred. The only large sample recorded from the area was taken between 1952 and 1964 at Didsbury, about 4 miles from the city centre ${ }^{1,2}$. In all, 760 moths were collected, consisting of $\mathbf{7 4 9}$ carbonaria and eleven of the intermediate melanic form insularia, typicals being unrepresented.

The environment of the peppered moth is again changing. Smoke control, started in 1952, has led to a marked reduction in the amount of soot in the air. Old, buildings blackened by smoke are being cleaned, and new ones are being constructed of light coloured fabrics. To investigate whether these current changes are reflected by the population of $B$. betrularia and of other polymorphic species of moths, between 1966 and $1969^{3}$ we collected the moths in mercury vapour light traps and assembling traps at sites between Prestwich to the north and Jodrell Bank some miles to the south of the conurbation. In all, $972 B$. betularia were recorded of which twelve were insularia and twenty-five were typicals. By Fisher's factorial test the difference between the frequency of typicals in this sample and in the returns for 1952-64 is very highly significant.

The form insularia is variable in phenotypic expression, sometimes approaching the typical in appearance. In the Manchester area specimens tend to the darker rather than the paler end of the range of variation, so that in this region there is no danger of confusing the two forms. After correspondence with $\mathrm{Mr} \mathrm{H}$. N. Michaelis, the collector of the earlier material, and examination of some of his specimens in the Manchester Museum, we are convinced that both sets of samples have been scored using the same criteria.

Some of the collecting sites at the southern end of the transect are quite rural in character, but the results are uniform over the entire length. Considering only moths in Didsbury and in Longsight, a more polluted locality two miles to the north, we obtained eight typicals and two insularia in 364 individuals. The frequency of typicals is again significantly different from the earlier one obtained from almost the same area $(P<0.0001)$, suggesting that there has been a recent resurgence of the typical form deep in the Manchester conurbation. Evidence of a small but significant increase in frequency of typical moths in the Liverpool area following the introduction of smoke control has been reported by Clarke and Sheppard 4 .

We thank colleagues in the Department of ZoologxManchester University, for collecting samples.

\section{M. Cook \\ R. R. ASKEW}

Department of Zoology,

The University, Manchester.

J. A. Bishor

Department of Zoology,

The University, Liverpool.

Received April 13; revised June 22, 1970.

${ }^{1}$ Kettlewell, H. B. D., Heredity, 12, 51 (1958).

S Kettlewell, H. B. D., Entomol. Rec., 77, 195 (1965),

${ }^{3}$ Askew, R. R., Bishop, J. A., and Cook, L. M., J. Appl. Ecol. (in the press),

‘ Clarke, C. A., and Sheppard, P. M., Proc. Roy. Soc., B, 165, 424 (1966).

\section{Synthesis of a Mucous Cuticle by a Zoanthid}

MANY zoanthids (Coelenterata, Zoantharia) are known to produce a secretion which lies external to the epidermis ${ }^{1}$. This structure is termed a "cuticle". Although it has been assumed that the cuticle is secreted by the epidermis, direct evidence of this is lacking. The source of substrates used in the synthesis of the cuticle is also unknown.

During studies on the movement of photosynthetic products of zooxanthellae to the tissues of their animal hosts, it was noticed that in Zoanthus sp., photosynthetically fixed ${ }^{14} \mathrm{C}$ moved from the algae in the animal's gastroderm to the epidermis, and was then incorporated into the substance of the cuticle as it was secreted by the epidermis.

Specimens of Zoanthus sp. were collected at Punta Piñasco, Baja California, Mexico. They were maintained. in seawater aquaria at $20^{\circ}-23^{\circ} \mathrm{C}$ under constant aeration and daily illumination of about 1,000 foot candles. Ther were used in experiments within 5 days after collection.

The animals were incubated in the light and in the dark for $1 \mathrm{~h}$ in seawater to which $\mathrm{NaH}^{14} \mathrm{CO}_{3}$ was added to. give an initial activity of $10 \mu \mathrm{Ci} / \mathrm{ml}$. Specimens incubated in the light were then transferred to unlabelled sea water in the light. Specimens incubated in the dark were first placed in unlabelled seawater in the dark for $6 \mathrm{~h}$ before transfer to the light, to ensure that residual unincorporated $\mathrm{H}^{14} \mathrm{CO}_{3}^{-}$had been washed out from the tissues. $6 \mathrm{~h}$ after the end of the incubation, one dark-incubated and one light-incubated specimen were fixed in Bouin's solution. The dark-incubated specimens were then separately transferred to the light in fresh unlabelled seawater and all were exposed to daily illumination. At daily intervals for the first 10 days, and every 2 days subsequently for a total of 25 days, light and dark-incubated specimens were fixed. Specimens were prepared for autoradiography according to a method previously described2,8. Paraffin embedded sections were cut at 5-7 $\mu \mathrm{m}$, and tissues were exposed to Kodak NTB-2 liquid emulsion for 9 days and developed as suggested by the manufacturers. 